\title{
Novel structural features of the immunocompetent ceramide phospho-inositol glycan core from Trichomonas vaginalis
}

Christian Heiss, ${ }^{\mathrm{a}, \star}$ Zhirui Wang, ${ }^{\mathrm{a}}$ Ian Black, ${ }^{\mathrm{a}}$ Parastoo Azadi, ${ }^{\mathrm{a}}$ Raina N. Fichorova ${ }^{\mathrm{b}}$, and Bibhuti N. Singh ${ }^{\mathrm{c}, *}$

${ }^{a}$ Complex Carbohydrate Research Center, The University of Georgia, 315 Riverbend Road, Athens, GA 30602, USA

${ }^{\mathrm{b}}$ Department of Obstetrics, Gynecology and Reproductive Biology, Brigham and Women's Hospital, Harvard Medical School, 221 Longwood Avenue, Boston, MA 02115, USA

${ }^{\mathrm{C} D e p a r t m e n t ~ o f ~ B i o c h e m i s t r y ~ a n d ~ M o l e c u l a r ~ B i o l o g y, ~ S U N Y ~ U p s t a t e ~ M e d i c a l ~ U n i v e r s i t y, ~}$ 750 E Adams St, Syracuse, NY 13210, USA

Corresponding authors; $a^{*}+1-706-542-3008$, cheiss@uga.edu (Christian Heiss) $c^{*}+1-315-464-5398$, singhb@upstate.edu (B.N. Singh); 


\begin{abstract}
The ceramide phosphoinositol glycan core (CPI-GC) of the lipophosphoglycan of Trichomonas vaginalis is a major virulent factor of this common genitourinary parasite. While its carbohydrate composition has been reported before, its structure has remained largely unknown. We isolated the glycan portions of CPI-GC by nitrous acid deamination and hydrofluoric acid treatment and investigated their structures by methylation analysis and 1- and 2-D NMR. We found that the $\alpha$-anomer of galactose is a major constituent of CPI-GC. The $\beta$-anomer was found exclusively at the nonreducing end of CPI-GC side chains. Furthermore the data showed that the rhamnan backbone is more complex than previously thought and that the inositol residue at the reducing end is linked to a 4-linked a-glucuronic acid (GIcA) residue. This appears to be the most striking and novel feature of this GPI-anchor type molecule.
\end{abstract}

\title{
Keywords
}

Trichomonas vaginalis, glycoconjugates, phospho-inositol glycan core, NMR 


\section{Introduction}

Human trichomoniasis is caused by an extracellular urogenital protozoan parasite, Trichomonas vaginalis. It is the most common non-viral sexually transmitted infection ( 180 million people) world-wide. $T$. vaginalis adheres to and damages vaginal epithelial cells ${ }^{1}$ and lives in the vagina and the male urethra. ${ }^{2}$ In addition to being a serious cause of discomfort and the leading cause of vaginitis, the infection has been linked to a myriad of reproductive problems e.g. preterm delivery, low birth weight, and infertility, bacterial vaginosis, risk of HIV infection and transmission, HPV infection and cancer. ${ }^{3-8}$ The infection is often recurrent with no lasting immunity implying the importance of the innate immune defenses. Almost half of the women diagnosed with trichomoniasis are asymptomatic while the others develop a severe inflammatory reaction, which is an additional risk factor for HIV acquisition and other viral infections. $^{9,10}$

Parasitic protozoan contain a variety of complex carbohydrates on their surfaces, e.g., glycolipids, glycoproteins, and glycosylated phosphatidylinositol glycolipids (GPI). ${ }^{11-15}$ These surface glycoconjugates are known to play intrinsic roles in cell to cell interactions, host cell invasion and evasion of host responses. ${ }^{11,12,15}$

T. vaginalis contains a predominant GPI-anchored cell surface lipophosphoglycan (TV-LPG) that is involved in adherence of parasites to cervical epithelial cells, ${ }^{13,16}$ and that LPG from vaginal isolates elicits a selective and speciesspecific production of cytokines by human female genital tract epithelial cells. ${ }^{1,17}$ We have previously reported the biochemical nature of TV-LPG derived from a proinflammatory $T$. vaginalis isolate (UR1) $)^{1,13,15}$ and have also demonstrated that the 
specific molecular domain of LPG, the ceramide phospho-inositol glycan core (CPI-GC) is required for triggering immunoinflammatory pathways in human vaginal and cervical epithelia ${ }^{15}$ and amplifies inflammatory responses to vaginal bacteria. ${ }^{18} \mathrm{~A}$ schematic diagram of $T$. vaginalis LPG and its substructure, CPI-GC, was previously published by Singh et al.. ${ }^{15}$ TV-LPG is analogous to the LPGs from other parasites such as Leishmania but is clearly distinct from them in its monosaccharide composition and other structural features. Leishmania LPG is a polymer of $[6)-\beta-G a l-(1 \rightarrow 4)-\alpha-M a n-1-P-$ $(\mathrm{O} \rightarrow$ ] repeating units attached to a glycan core that is embedded into the membrane via a 1-O-alkyl-2-lyso-phosphatidylinositol anchor. ${ }^{19}$ TV-LPG contains no protein/peptide (unlike other GPI-anchored molecules) and no mannose, and is anchored via inositolphosphate-ceramide. ${ }^{14,15}$ The CPI-GC and TV-LPG contain terminal non-reducing $\beta$ galactosyl residues and lactosamine repeats, providing the molecular basis of CPI-GC interactions with the galectin family of host proteins, which has emerged as regulators of innate and adoptive immunity and host-pathogen interactions. ${ }^{20-22}$

TV-CPI-GC has been shown to be composed of the monosaccharide building blocks rhamnose (Rha), galactose (Gal), glucosamine (GlcN), and xylose (Xyl). Recently, Ryan et al. ${ }^{23}$ published a thorough MS analysis of oligosaccharides released by mild acid hydrolysis of LPG (which they called lipoglycan) derived from a laboratory T. vaginalis strain (B7RC2). By combining these results with those of methylation analysis of partially depolymerized LPG, these authors were able to propose a new model of the LPG structure. Building upon this model, we have used extensive NMR analysis to refine and correct some aspects of the LPG structure. In particular, we propose the $\mathrm{Gal}$ in the core (CPI-GC) to have predominantly a-anomeric configuration, 
in contrast to the previously suggested $\beta$-configuration. In addition, we detected the presence of major amounts of phosphoethanolamine and phosphocholine in CPI-GC.

Finally, we propose a novel reducing end motif, comprising a $\rightarrow 4$ )-a-GlcA-(1 $\rightarrow 4)-$ myoinositol (Ins) linkage.

Understanding the chemical nature of this major immunocompetent molecule would have important implication to develop effective therapeutic drug to treat human trichomoniasis.

\section{Results}

\subsection{NMR analysis of nitrous acid- delipidated CPI-GC (CPI-GC-N)}

For structural analysis of the glycan portion of CPI-GC, we removed its lipid portion by treatment with nitrous acid ${ }^{13,15}$ to achieve sufficient solubility in aqueous solution. The released lipid was removed by Folch extraction, and the resulting glycan core, which was named "CPI-GC-N" (N stands for Nitrous acid) was subjected to methylation analysis and 1- and 2-D NMR analysis.

The methylation analysis of the glycan core revealed a complex mixture of linkages (Table 1). The predominant linkages were terminal and 3-linked Gal and 3linked and 4-linked GlcN (the linkage analysis does not distinguish between GlcNAc and GlcN). Rha was present in several different linkages, including terminal, 2-linked, 3linked, 2,3-linked, and 2,4-linked. All monosaccharides had the pyranose ring form.

The 1-D proton spectrum (Fig. 1) showed two large peaks in the $\alpha$-anomeric region, one major broad anomeric peak in the $\beta$-anomeric region, and several minor 
anomeric peaks in between. All of the major anomeric peaks had irregular line shapes, pointing to a structure with a very complex repeating unit or no repeating unit at all. The ring region extended from 4.4 to $3.4 \mathrm{ppm}$. Just upfield from this region we observed two large singlets whose proton and carbon chemical shifts (from HSQC) were in agreement with phosphocholine (PCho) ${ }^{24}$ and phospoethanolamine (PEtN) ${ }^{25}$ diesters, as opposed to monoesters. ${ }^{26,27}$ Around 2 ppm were found several overlapping $\mathrm{N}$-acetyl peaks belonging to the GlcNAc residues and between 1.4 and $1.2 \mathrm{ppm}$ a number of overlapping 6-deoxysugar methyl signals (not shown).

In the 2-D COSY spectrum of CPI-GC-N, at least 20 separate spin systems were discernible. Using TOCSY, HSQC (Fig. 1), and NOESY spectra, 14 of these could be assigned to specific monosaccharides. The partial assignment can be found in Table 2 . The residues $\alpha-$ Gal and $\alpha$-Rha were clearly discernible by their TOCSY patterns. Gal typically shows three cross peaks correlated with $\mathrm{H}-1$ because of the large vicinal coupling constants of $\mathrm{H}-1$ through $\mathrm{H}-4$ and the small coupling constant between $\mathrm{H}-4$ and $\mathrm{H}-5$. Also typical for $\alpha-G a l$ is the rather low field chemical shift of $\mathrm{H}-4$. Two spin systems, with $\mathrm{H}-1$ at 5.51 and $5.45 \mathrm{ppm}$, showed an $\alpha$-galacto pattern in the TOCSY spectrum. ${ }^{28}$ The $\alpha$-stereochemistry of these residues was indicated by the downfield chemical shift of their $\mathrm{H}-1$ protons and by anomeric one-bond $\mathrm{C}-\mathrm{H}$ coupling constants of 183 and $178 \mathrm{~Hz}$, respectively. ${ }^{29}$ The $\mathrm{C}-3$ nuclei of both galactose residues resonated at 82.3 ppm indicating glycosylation in the 3-position. This was confirmed by an $\mathrm{H}-4$ chemical shift of $4.20 \mathrm{ppm}$, consistent with 3-linked $\alpha$-galactose. A GlcA residue was found with $\mathrm{H}-1$ at $5.32 \mathrm{ppm}$ and $\mathrm{H}-5$ at $4.77 \mathrm{ppm}$. This residue was not found in the 
methylation analysis, because detection of uronic acids by GC-MS requires prior carboxyl reduction, which we did not perform.

The major signal in the $\beta$-anomeric region was found, by 2-D COSY, to consist of at least two anomeric protons, both of them from GlcNAc residues. The two different spin systems were most likely from 3-linked and 4-linked $\beta$-GlcNAc.

The NOESY spectrum of CPI-GC-N connected the Gal H-1 at $5.51 \mathrm{ppm}$ to $\mathrm{H}-3$ of the $3-\beta-G I c N A c$ residue and the Gal $\mathrm{H}-1$ at $5.45 \mathrm{ppm}$ to $\mathrm{H}-4$ of the $4-\beta-\mathrm{GlcNAc}$ residue. Due to overlap of intra- and inter-residue NOE correlations, the residues attached to $\mathrm{H}-1$ of the GIcNAc residues could not be clearly identified, although a cross peak at 4.70/4.20 ppm suggested connectivity between 4-GlcNAc and 3- $\alpha-$ Gal. These results, together with the fact that the $\mathrm{H}-1$ signals of $\alpha-\mathrm{Gal}$ and $\beta-\mathrm{GlcNAc}$ are by far the largest in the anomeric region of the 1-D spectrum, indicate that a major part of the polysaccharide is comprised of chains of $[3)-\alpha-$ Gal- $(1 \rightarrow 3)-\beta-$ GIcNAc- $(1 \rightarrow]$ and $[3)-\alpha-$ Gal-(1 $\rightarrow 4)-\beta$-GlcNAc- $(1 \rightarrow]$ disaccharide repeating units. The presence of terminal GalNAc and terminal $\beta$-Gal suggests that the chains are either terminated at the nonreducing end with GalNAc and $\beta-$ Gal or that the chains have some GalNAc and $\beta$-Gal side chains. This may explain the binding of CPI-GC with galectin-1, which requires non-reducing terminal $\beta$-galactoside (terminal $\beta$-Gal attached to GlcNAc) ${ }^{20,21}$ Xylose was identified by its characteristic $\mathrm{C} / \mathrm{H}-5$ pattern and is shown to be in the $\beta$-anomeric configuration by its upfield anomeric proton signal.

Most of the small signals in the 1-D spectrum (Fig. 1) between the two major signals arise from different $\alpha$-rhamnose residues. These rhamnose residues were 
identified by their low-field $\mathrm{H}-2$ resonances and the presence of at most two correlations with $\mathrm{H}-1$ in the TOCSY spectrum. Due to their low intensity, the assignment of these residues is tentative. The NMR data confirm the finding from methylation analysis that the majority of the Rha residues are 2-linked or 3-linked, and some may be 2,3- or 2,4linked. This suggests that part of the polysaccharide is a rhamnan without regular repeating unit.

The spectra also showed evidence of the presence of a significant amount of both phosphoethanolamine (PEtN) and phosphocholine (PCho). At present, it is not clear if or how these substituents are attached to CPI-GC-N. Work is currently underway to localize these groups.

CPI-GC-N was treated with $\alpha-$ galactosidase [EC 3.2.1.22] alone and in combination with $\beta-\mathrm{N}$-acetyl hexosaminidase [EC 3.2.1.52]. We performed two types of monosaccharide analysis using both high $\mathrm{pH}$ anion exchange chromatography (HPAEC-PAD), as well as GC-MS after trimethylsilyl (TMS) derivatization of the released monosaccharides and found Gal and GlcNAc, with more Gal being detected when both enzymes were used.

\subsection{NMR analysis of dephosphorylated CPI-GC (CPI-GC-F)}

CPI-GC was treated with aqueous HF in order to remove the PEtN and PCho substituents, as well as the phosphate-bound lipid. The methylation analysis (Table 1) of the resulting material, which was named "CPI-GC-F" (F stands for hydroFluoric acid) showed the same linkage patterns as that of CPI-GC-N, except that it contained less terminal residues and that it detected 4-linked Rha linkages, which were not found in 
CPI-GC-N. The lower proportion of terminal residues may be caused by some losses due to the acidic $\mathrm{pH}$ during the $\mathrm{HF}$ treatment. ${ }^{30}$ The methylation analysis data gave no indication as to the location of the phosphate bound groups in PEtN and PCho. The NMR spectra clearly showed the loss of the signals belonging to the PEtN and PCho groups, but also failed to locate the attachment site of these groups. The dephosphorylation led to spectra of significantly improved quality, showing sharper linewidths and enhanced sensitivity. As a result, an even greater complexity of the CPIGC structure than previously appreciated was revealed. However, the main structural motif was again the $[3)-\alpha-G a l p-(1 \rightarrow 4)-\beta-G l c p N A c-(1 \rightarrow]$ disaccharide that was also detected in CPI-GC-N. Figure 2 shows the 2D COSY, HSQC, and HMBC spectra of CPI-GC-F at a high contour level, i. e. showing only the most intense peaks. This presentation highlights the predominance of the two major spin systems. On the other hand, the anomeric region of the TOCSY spectrum in Figure $\mathbf{3}$ is presented at a lower contour level, visualizing the multitude of minor peaks corresponding to the many different monosaccharide residues present in CPI-GC. We were able to assign or partially assign 36 individual monosaccharide residues (Table 3), but a few of the spin systems had to remain unassigned. Many of the spin systems represented the same type of monosaccharide (e. g. 2-linked a-Rha), their differences apparently arising from heterogeneity in the neighboring residues. The greatest variability was found among the a-Rha residues, with four 2-linked, six 3-linked, and four 2,3-linked variations. On the other hand, only a single species was found of 4-linked GlcA and 4-linked myo-Ins, although both of these were present in significant abundance. Two variations of 3-linked $\alpha-G a l$ were detected, of which one (Residue $\left.A_{1}\right)$ was attached to 4-linked $\beta$-GIcNAc 
(Residue $B_{1}$ or $B_{2}$ ), while the other was attached to 3 -linked $\beta$-GlcNAc (Residue $C_{1}$ or $C_{2}$ ). The last major group of residues was a set of five different terminal $\beta$-Xyl variations. Minor residues included terminal $\alpha$ - and $\beta$-Gal, 4-linked and 3,4-linked $\alpha$-Gal, 3-linked $\alpha$ and $\beta$-Glc, terminal $\beta$-Glc, as well as terminal and 6 -linked $\beta$-GlcNAc.

After the assignment of most of the spin systems was done, we quantified each assigned or partially assigned monosaccharide by deconvolution and line fitting of the anomeric region of the resolution-enhanced 1D proton spectrum. Where the anomeric signals of two residues overlapped, as well as for the inositol residue, which does not have an anomeric proton, we utilized peak volume integration of well resolved peaks in the $2 \mathrm{D} \mathrm{HSQC}$ spectrum to estimate the contributions of the overlapping signals. Although there were some spin systems that could not be assigned, the results of this analysis agreed very well with the glycosyl composition analysis of CPI-GC-F (Table 4). This agreement strengthens the validity of the NMR assignments.

A 2D NOESY experiment (Fig. 4) was used to identify di- and trisaccharide building blocks that make up the CPI-GC structure. Figure 5A shows the motifs that were found by this method, and Figure 5B shows the derived structural model. Beside the connections between the 3-linked $\alpha-G a l$ and 4 -linked $\beta$-GlcNAc residues of the main repeats (Motif 1), several other di- and oligosaccharide sequences were identified. Motif 5 includes a substitution of 3-linked $\beta$-Glc for 4 -linked $\beta$-GlcNAc. It is unclear whether this substitution occurs only in this position, near the non-reducing end, and whether all non-reducing termini include the 3 -linked $\beta$-Glc residue. Motifs 5, 8, and 9 represent branch points, i. e. attachment points of side chains to the backbone or of secondary side chains to primary side chains. Motifs 7 and 8 are examples of secondary side 
chains terminating in $\beta-X y l$. The branch point in Motif 8 suggests that there are even tertiary side chains present in this complicated molecule. Motif 3 may be a truncated version of Motif 9, i. e. a secondary side chain attached to the non-reducing end residue of a primary side chain.

Motif 4 represents the reducing end of the polysaccharide, which was released by the HF-treatment through cleavage of the inositol-phosphate bond. Inter-residue correlations in the NOESY (5.27/3.71 ppm, Figure 6 top) and HMBC (5.27/83.0 and 3.71/101.7 ppm, Figure 6 bottom) spectra indicated that the inositol moiety was linked through its $0-4$ to an $\alpha-$ GlcA residue that was in turn glycosylated on O-4 by a 3-linked a-Glc. In fact, the NOESY spectrum shows additional cross peaks between the GlcA anomeric proton and $\mathrm{H}-3, \mathrm{H}-4$, and $\mathrm{H}-5$ of inositol, which is exactly what would be expected from a GlcA-(1 $\rightarrow 4)-$ Ins linkage (Figure 7).

\section{Discussion}

The data presented here are from the biologically active components of $T$. vaginalis (UR-1 strain) LPG, the CPI-GC. ${ }^{15}$ Earlier, we reported several structural features as well as the biological relevance of CPI-GC, including the presence of lactosamine repeats. ${ }^{15}$ The NMR studies reported here greatly expand our understanding of the intricate chemical nature of this complex glycan.

The structure of the UR1 CPI-GC has some similarities with the one proposed by Ferguson and Johnson's group ${ }^{23}$ for LPG (which they renamed as lipoglycan) from another strain of $T$. vaginalis (B7RC2). There are several points of agreement between the structural model proposed for that strain and the data presented here. These include 
a main backbone consisting of $\alpha$-Rha residues, major primary side chains made up of $[3)-$ Gal-( $1 \rightarrow 4)-\beta-$-GlcNAc- $(1 \rightarrow]$ repeats, and short secondary side chains of $\beta-X y l-(1 \rightarrow 2)-$ a-Rha, attached to O-4 of $\alpha-G a l$ residues in the primary side chains. Thus, our data confirm the basic model put forth previously. However, there are two major aspects of disagreement and several new insights uncovered by our research. The major discrepancy lies in the anomeric configuration of the majority of the Gal residues, which we have conclusively shown to be $\alpha$. In fact, the only $\beta$-Gal we found was terminal, indicating that it is present only at the non-reducing end of some (or all) side chains, which is consistent with previously reported strong binding of the lectins RCA-1 $1^{13,22,31}$ and galectin- $1^{13,20-22,31}$ We have recently demonstrated that both the UR1 and the B7RC2 CPI-GCs bind to RCA-1 and galectin-1. The fact that treatment of CPI-GC with exo- $\beta$-galactosidase [EC3.2.1.23] did not abolish galectin-1 binding (unpublished observation) could mean that there is either a small amount of internal $\beta-G a l$, which we were unable to detect, or that the enzyme is sterically hindered from completely removing all of the $\beta$-Gal at the non-reducing ends. The report by Ryan et al., ${ }^{23}$ as well as our own previous research ${ }^{15}$ attempted to determine the Gal anomeric configuration mainly by exo-glycosidase digestion. The former supplemented the analysis by a crude NMR analysis. According to Ryan et al., $\alpha$-galactosidase treatment had no effect on the polysaccharide. However, in that report the polysaccharide was treated either with the mixture of $\beta$-galactosidase and hexosaminidase or with $\alpha$-galactosidase alone. The authors performed several combinations of these two treatments, but failed to examine digestion with the mixture of $\alpha$-galactosidase and hexosaminidase (which could cause a significant release of Gal). Therefore, they would have been unable to release a 
significant amount of Gal if, as we suggest here, the $\alpha$-Gal occurs as part of an $\alpha-G a l-\beta$ GIcNAc disaccharide repeating unit. Additionally, if all or most of the side chains are in fact terminated by $\beta-G a l$, as our NMR analysis indicates, exo- $\alpha$-galactosidase treatment would have likewise failed due to absence of terminal $\alpha-G a l$ residues. However, when we did the experiment with both $\alpha$-galactosidase and hexosaminidase, we indeed observed a moderate release of Gal from the polysaccharide, indicating that at least some of the side chains have $\alpha-G a l$ at the non-reducing end. We have observed a similar release when we treated TV-B7RC2 CPI-GC with these enzymes (data not shown).

In spite of their failure to release Gal by digestion with $\alpha$-galactosidase, Ryan et al. claimed to have found $\alpha-G a l$ by NMR. Unfortunately however, the spectra were incorrectly assigned in that report, as the sugar residues were apparently identified only by $\mathrm{H}-1$ chemical shifts without consideration of $\mathrm{H}-2$ chemical shifts, which are characteristically different for terminal or 3-linked $\alpha-G a l$ on one hand (3.7-3.9 ppm) and $\alpha-R h a$ on the other (>4 ppm). The incorrect anomeric assignment of the Gal residues in our previous work ${ }^{15}$ and in the otherwise excellent report by Ryan et al. ${ }^{23}$ illustrates the pitfalls of relying mainly on enzymatic treatments for the determination of anomeric configuration, without rigorous NMR analysis. This is especially critical in the case of a highly branched polysaccharide such as $\mathrm{CPI}-\mathrm{GC}$, where steric hindrance can potentially abolish enzymatic activity, as Ryan et al. themselves have pointed out. If the $\beta$-Gal residues are predominantly located at the non-reducing ends of side chains, which are composed mostly of the a-anomer of Gal, as our results suggest, then it is not surprising 
that treatment with exo-a-galactosidase released only a small amount of Gal and provided potentially misleading results.

In agreement with the model proposed by Ryan et al., ${ }^{23}$ the structural motifs we identified showed the 3-position of Rha to always be substituted by another Rha (Motifs 2 and 6), whereas the 2-position was always substituted by Xyl (Motifs 7 and 8 ) or GlcNAc (Motif 5). However, we observed greater diversity of Rha residues in the NMR spectra than would be expected from the regular 2,3-homorhamnan backbone proposed in the model. We were able to identify $14 \alpha$-Rha residues in the 2D NMR analysis, but it is likely that the number of different Rha residues may be much larger, as indicated by the multitude of minor peaks in the anomeric region of the TOCSY spectrum and of overlapping peaks in the $\mathrm{H}-6$ region of the COSY spectrum. This diversity suggests a more complex rhamnan backbone structure than previously thought.

Motif 4 represents the reducing end of the polysaccharide with Ins at its terminus. CPI-GC has long been known to be attached to ceramide through an Ins-phosphate linkage. ${ }^{13-15}$ We took advantage of the selective removal of phosphate by HF in order to separate the ceramide moiety from the polysaccharide, which is then terminated by myo-Ins. What is surprising is that the NMR evidence, consisting of several correlations in both NOESY and HMBC, rather conclusively points to $\alpha-G I c A$ as the penultimate residue. This is in contrast to the previous understanding that Ins is attached to a nonacetylated glucosamine or galactosamine ${ }^{13-15}$ as reported in most of the GPI-anchored molecules studied so far. ${ }^{11,19}$ However, there is clear evidence that treatment with nitrous acid cleaves the lipid, together with the Ins residue from the polysaccharide. This reactivity has previously been explained by the presence of a non-acetylated GlcN next 
to the Ins residue. We should have been able to detect GlcN in the HF-treated sample, but did not find any evidence for such an aminosugar in the NMR analysis. Instead, we discovered Motif 4, in which the inositol residue is attached to a 4-linked $\alpha-G l c A$ residue. This linkage was indicated by cross peaks in both NOESY and HMBC spectra. It is possible that GlcN is not directly attached to Ins, but is located one or more monosaccharide units closer to the non-reducing end. However, the GlcA residue would have been removed also in that case, even though a-GlcA was also found in CPI-GC-N. On the other hand, that GlcA (Residue D, Table 2) may not be the same as Residue D in CPI-GC-F (Table 3). Based on the motifs we have identified, we propose a refined structural model for CPI-GC that is consistent with all the NMR data (Figure 5B). Our findings are very interesting and broadly novel, adding new dimensions to the studies of GPI-anchor molecules in eukaryotes. It is clear that further research is needed to answer the important questions posed by our study and to complete the structural characterization of $T$. vaginalis CPI-GC.

\section{Experimental}

\subsection{Isolation of CPI-GC}

A previously immunologically well characterized $T$. vaginalis clinical isolate UR1 was grown in Dr. Fichorova's laboratory as described. ${ }^{1,15,17,18}$ LPG was extracted from UR1 followed by CPI-GC purification in Dr. Singh's laboratory as reported earlier. ${ }^{15}$ Briefly, a known amount of LPG was hydrolyzed with 100 mM TFA containing DTT (1 $\mu \mathrm{g} / \mathrm{ml}$ ) under vapor phase at $100{ }^{\circ} \mathrm{C}$ for $3 \mathrm{~h}$. Hydrolysates were dried with 2-propanol and resuspended in $0.1 \%$ TFA and placed onto a preconditioned C18-Sep-Pac (Waters 
Corp.). The column was first washed with $0.1 \%$ TFA ( $3 \mathrm{ml})$ to obtain released saccharide(s) and the retained lipid containing glycan (CPI-GC) was eluted with $30 \%$, $50 \%$, and $70 \%$ n-propanol sequentially. An aliquot was set aside for NMR analyses. CPI-GCs from other strains such as $T$. vaginalis strain $B 7 R C 2{ }^{23}$ were prepared in the same way.

\subsection{Enzymatic treatments}

Known amounts of CPI-GC were treated with a-galactosidase [EC 3.2.1.22] from green coffee beans (Sigma Co.) in sodium phosphate buffer ( $\mathrm{pH} 6.4$ ) for $48 \mathrm{~h}$. The sample was then acidified with 0.4 M TFA and applied to C18-SepPac column. Released monosaccharides were eluted with $0.1 \%$ TFA and the remaining lipid containing glycan eluted with $30 \%, 50 \%$, and $70 \%$ n-propanol sequentially. In some cases, CPI-GC was treated with $\alpha$-galactosidase followed by $\beta-\mathrm{N}$-acetylhexosaminidase [EC 3.2.1.52] (recombinant clone from S. plicatus, obtained from New England Bio Labs) for $24 \mathrm{~h}$ in buffer supplied by manufacturer (after adjusting to the desired $\mathrm{pH}$ ). At the end of the reaction, the sample was acidified with 0.4 M TFA and purified as described above. An aliquot containing lipid-glycan was submitted to NMR analysis. In some cases CPI-GC was treated with either $\beta$-galactosidase [EC 3.2.1.23] from recombinant clone from Bacteroides fragilis (obtained from New England Bio Labs) alone or in combination with $\beta$-N-acetyl hexosaminidase for $24 \mathrm{~h}$ in buffer supplied by the manufacturer. Released fractions were dried by SpeedVac concentrator. All of the experimental aqueous eluates containing saccharide(s) were further purified on a Dowex 1X8 (anion exchange) and Dowex 50W-X8 (cation exchange, hydroxide and 
hydrogen) resin. The resultant eluates were dried and analyzed for monosaccharides by HPAE-PAD HPLC (Carbo-Pak PA-1 column) as reported earlier. ${ }^{32}$ Monosaccharides released by $\alpha$-galactosidase treatment alone or in combination with hexosaminidase were derivatized by TMS and analyzed by GC-MS to confirm the release of $\alpha-\mathrm{Gal}$ and GlcNAc.

\subsection{Nitrous Acid Cleavage and Folch Extraction}

CPI-GC (3.5 mg) was dissolved in $200 \mu \mathrm{L} 50$ \% 1-PrOH with sonication, cooled in ice, and treated with $200 \mu \mathrm{L}$ ice-cold $0.5 \mathrm{M}$ nitrous acid [prepared from equal volumes of $0.5 \mathrm{M} \mathrm{H}_{2} \mathrm{SO}_{4}$ and $\left.0.5 \mathrm{M} \mathrm{Ba}\left(\mathrm{NO}_{2}\right)_{2}\right]{ }^{33}$ The sample was rotated at $4{ }^{\circ} \mathrm{C}$ for $24 \mathrm{~h}$ and then concentrated by a stream of dry nitrogen. For the isolation of the glycan, the sample was extracted first with $2 \mathrm{~mL} 2: 1 \mathrm{CHCl}_{3}-\mathrm{MeOH}$, vortexing for $5 \mathrm{~min}$. Then 400 $\mu \mathrm{L}$ water was added, and vortexing was continued for $15 \mathrm{~min}$. After centrifugation three layers were obtained, a clear organic layer at the bottom, a clear aqueous layer at the top, and a white interface in the middle. NMR spectra of each layer were acquired at $600 \mathrm{MHz}$ after evaporation and dissolving in $\mathrm{D}_{2} \mathrm{O}$ (top layer), pyridine- $\mathrm{d}_{5}$ (interface), and chloroform-d (bottom). The bottom layer contained the lipid; the interface showed only 1-PrOH, and top layer contained the polysaccharide.

\subsection{HF-Treatment}

The sample was freeze-dried, treated with $200 \mu \mathrm{L}$ hydrofluoric acid $(48 \%),{ }^{34}$ and incubated for 48 hours at $4{ }^{\circ} \mathrm{C}$. Then the solution was neutralized with $1 \mathrm{M} \mathrm{NaOH}$ in an ice bath. The neutralized sample was then desalted by passage through a G15 column $(2.5 \times 50 \mathrm{~cm})$ and freeze-dried for NMR analysis. 


\subsection{NMR Spectroscopy}

For the NMR experiments, the sample was deuterium-exchanged by lyophilization from $\mathrm{D}_{2} \mathrm{O}\left(99.9 \% \mathrm{D}\right.$, Aldrich). The sample was then dissolved in $\mathrm{D}_{2} \mathrm{O}$ $(99.96 \% \mathrm{D}, \mathrm{CIL})$ at a concentration of about $50 \mathrm{mg} / \mathrm{mL}$. Acetone was added as internal reference at $\sim 5 \mu \mathrm{g} / \mathrm{mL}$. One-dimensional proton and 2-dimensional ${ }^{1} \mathrm{H}-{ }^{1} \mathrm{H}-\mathrm{TOCSY}$, NOESY, gradient-enhanced COSY, and ${ }^{1} \mathrm{H}^{-13} \mathrm{C}$-gradient-enhanced HSQC and HMBC spectra were obtained on a Varian Inova-600 $\mathrm{MHz}$ spectrometer at $25{ }^{\circ} \mathrm{C}$ using standard Varian pulse sequences. One-bond ${ }^{1} \mathrm{H}^{-13} \mathrm{C}$ anomeric coupling constants were measured using a ${ }^{1} \mathrm{H}^{13} \mathrm{C}$ HSQC experiment without decoupling during acquisition. Proton chemical shifts were measured relative to internal acetone $\left(\delta_{\mathrm{H}}=2.218 \mathrm{ppm}\right.$, $\left.\delta_{\mathrm{C}}=33.0 \mathrm{ppm}\right) .{ }^{35}$ TOCSY and NOESY mixing times were 80 and $300 \mathrm{~ms}$, respectively. For all experiments the spectral width was $4.4 \mathrm{kHz}$ in the proton dimension and, for $\mathrm{HSQC}$ and $\mathrm{HMBC}, 18 \mathrm{kHz}$ in the carbon dimension.

\subsection{Methylation Analysis}

The nitrous acid-treated sample was permethylated by the method of Anumula and Taylor. ${ }^{36}$ Briefly, the sample was dissolved in $200 \mu \mathrm{L}$ DMSO and treated with 350 $\mu \mathrm{L}$ of a $\mathrm{NaOH}$ suspension (about $1 \mathrm{M}$ in DMSO). After $10 \mathrm{~min}, 100 \mu \mathrm{L}$ iodomethane was introduced, and the mixture was left to stand for $40 \mathrm{~min}$. The base/iodomethane treatment was repeated once. Excess methyl iodide was evaporated under a stream of nitrogen, and the permethylated sample was extracted with dichloromethane, concentrated by evaporation, and hydrolyzed with $300 \mu \mathrm{L} 2 \mathrm{M}$ trifluoroacetic acid, by incubation at $121^{\circ} \mathrm{C}$ for $2 \mathrm{~h}$ in a sealed tube. After drying, the released 
monosaccharides were reduced overnight with $400 \mu \mathrm{L} 10 \mathrm{mg} / \mathrm{mL} \mathrm{NaBD}_{4}$ in $1 \mathrm{M} \mathrm{NH}_{4} \mathrm{OH}$. The mixture was neutralized with glacial $\mathrm{AcOH}$, borate was removed by co-evaporation with $\mathrm{MeOH}$ and $\mathrm{AcOH}$, and the partially methylated alditols were acetylated at $100{ }^{\circ} \mathrm{C}$ for 60 min with a solution of $250 \mu \mathrm{L}$ acetic anhydride in $250 \mu \mathrm{L}$ pyridine. The resulting partially methylated alditol acetates were analyzed on a Hewlett Packard 5890 gas chromatograph interfaced to an Agilent 5970 mass selective detector in electron impact mode; separation was performed on a 30 m Alltec EC-1 fused silica capillary column.

\section{Acknowledgments}

This work was supported by the National Institute of Allergy and Infectious Diseases, 5R011 Al079085-04 (to Raina Fichorova and B. N. Singh), the Chemical Sciences, Geosciences and Biosciences Division, Office of Basic Energy Sciences, U.S. Department of Energy, grant DE-FG02-93ER20097 (to Parastoo Azadi), and by the National Institutes of Health (NIH)-funded Research Resource for Integrated Glycotechnology 5P41GM10339024( to Parastoo Azadi). 


\section{References}

1. Fichorova, R. N.; Trifonova, R. T.; Gilbert, R. O.; Costello, C. E.; Hayes, G. R.; Lucas, J. J.; Singh, B. N. Infect. Immun. 2006, 74, 5773-5779.

2. Singh, B. N.; Lucas, J. J.; Fichorova, R. N. In Emerging Protozoan Pathogens.; Khan, N. A., Jarrol, E. L., Eds.; Taylor \& Francis Group: London, 2007, pp 411-455.

3. Fichorova, R. N. J Reprod. Immunol.2009, 83, 185-189.

4. Quinlivan, E. B.; Patel, S. N.; Grodensky, C. A.; Golin, C. E.; Tien, H. C.; Hobbs, M. M. Sex. Transm. Dis. 2012, 39, 671-677.

5. Lazenby, G. B. Infect. Dis. Rep. 2011, 3, e4.

6. Gatski, M.; Martin, D. H.; Clark, R. A.; Harville, E.; Schmidt, N.; Kissinger, P. Sex. Transm. Dis. 2011, 38, 163-166.

7. Noel, J. C.; Fayt, I.; Romero Munoz, M. R.; Simon, P.; Engohan-Aloghe, C. Arch. Gynecol. Obstet. 2010, 282, 503-505.

8. Lazenby, G. B.; Taylor, P. T.; Badman, B. S.; McHaki, E.; Korte, J. E.; Soper, D. E.; Young Pierce, J. Clin. Ther. 2014, 36, 38-45.

9. Buve, A.; Jespers, V.; Crucitti, T.; Fichorova, R. N. AIDS 2014, 28, 2333-2344.

10. McClelland, R. S.; Sangare, L.; Hassan, W. M.; Lavreys, L.; Mandaliya, K.; Kiarie, J.; Ndinya-Achola, J.; Jaoko, W.; Baeten, J. M. J. Infect. Dis. 2007, 195, 698702.

11. Ferguson, M. A. J.; Kinoshita, T.; Hart, G. W. In Essentials of Glycobiology; 2nd ed.; Varki, A., Cummings, R. D., Esko, J. D., Freeze, H. H., Stanley, P., Bertozzi, C. R., Hart, G. W., Etzler, M. E., Eds.; Cold Spring Harbor Laboratory Press: Cold Spring Harbor (NY), 2009, pp 143-161. 
12. Nyame, A. K.; Kawar, Z. S.; Cummings, R. D. Arch. Biochem. Biophys. 2004, $426,182-200$

13. Singh, B. N. Mol. Biochem. Parasitol. 1993, 57, 281-294.

14. Singh, B. N.; Beach, D. H.; Lindmark, D. G.; Costello, C. E. Arch. Biochem. Biophys. 1994, 309, 273-280.

15. Singh, B. N.; Hayes, G. R.; Lucas, J. J.; Sommer, U.; Viseux, N.; Mirgorodskaya, E.; Trifonova, R. T.; Sassi, R. R.; Costello, C. E.; Fichorova, R. N. Glycoconj. J. 2009, 26, 3-17.

16. Bastida-Corcuera, F. D.; Okumura, C. Y.; Colocoussi, A.; Johnson, P. J. Eukaryot. Cell 2005, 4, 1951-1958.

17. Fichorova, R. N.; Lee, Y.; Yamamoto, H. S.; Takagi, Y.; Hayes, G. R.; Goodman, R. P.; Chepa-Lotrea, X.; Buck, O. R.; Murray, R.; Kula, T.; Beach, D. H.; Singh, B. N.; Nibert, M. L. PLoS One 2012, 7, e48418.

18. Fichorova, R. N.; Buck, O. R.; Yamamoto, H. S.; Fashemi, T.; Dawood, H. Y.; Fashemi, B.; Hayes, G. R.; Beach, D. H.; Takagi, Y.; Delaney, M. L.; Nibert, M. L.; Singh, B. N.; Onderdonk, A. B. Sex. Transm. Infect. 2013, 89, 460-466.

19. Guha-Niyogi, A.; Sullivan, D. R.; Turco, S. J. Glycobiology 2001, 11, 45r-59r. 20. Stowell, S. R.; Arthur, C. M.; Mehta, P.; Slanina, K. A.; Blixt, O.; Leffler, H.;

Smith, D. F.; Cummings, R. D. J. Biol. Chem. 2008, 283, 10109-10123.

21. Rabinovich, G. A.; Gruppi, A. Parasite Immunol. 2005, 27, 103-114.

22. Sato, S.; St-Pierre, C.; Bhaumik, P.; Nieminen, J. Immunol. Rev. 2009, 230, 172-187. 
23. Ryan, C. M.; Mehlert, A.; Richardson, J. M.; Ferguson, M. A.; Johnson, P. J. J. Biol. Chem. 2011, 286, 40494-40508.

24. Shi, F.; Harada, T.; Ogawa, Y.; Ono, H.; Ohnishi-Kameyama, M.; Miyamoto, T.; Eguchi, M.; Shimoji, Y. Infect. Immun. 2012, 80, 3993-4003.

25. Zahringer, U.; Ittig, S.; Lindner, B.; Moll, H.; Schombel, U.; Gisch, N.;

Cornelis, G. R. J. Biol. Chem. 2014, 289, 23963-23976.

26. Klein, M. S.; Buttchereit, N.; Miemczyk, S. P.; Immervoll, A. K.; Louis, C.;

Wiedemann, S.; Junge, W.; Thaller, G.; Oefner, P. J.; Gronwald, W. J. Proteome. Res. 2012, 11, 1373-1381.

27. Jewison, T.; Knox, C.; Neveu, V.; Djoumbou, Y.; Guo, A. C.; Lee, J.; Liu, P.; Mandal, R.; Krishnamurthy, R.; Sinelnikov, I.; Wilson, M.; Wishart, D. S. Nucleic Acids Res. 2012, 40, D815-820.

28. Agrawal, P. K. Phytochemistry 1992, 31, 3307-3330.

29. Bock, K.; Lundt, I.; Pedersen, C. Tetrahedron Lett. 1973, 14, 1037-1040.

30. Young, N. M.; Kreisman, L. S.; Stupak, J.; MacLean, L. L.; Cobb, B. A.;

Richards, J. C. Glycobiology 2011, 21, 1266-1276.

31. Okumura, C. Y.; Baum, L. G.; Johnson, P. J. Cell. Microbiol. 2008, 10, 20782090.

32. Zhang, Z.; Khan, N. M.; Nunez, K. M.; Chess, E. K.; Szabo, C. M. Analytical Chemistry 2012, 84, 4104-4110.

33. Shively, J. E.; Conrad, H. E. Biochemistry 1976, 15, 3932-3942.

34. Moody-Haupt, S.; Patterson, J. H.; Mirelman, D.; McConville, M. J. J. Mol. Biol. 2000, 297, 409-420. 
35. Wishart, D. S.; Bigam, C. G.; Yao, J.; Abildgaard, F.; Dyson, H. J.; Oldfield, E.; Markley, J. L.; Sykes, B. D. J. Biomol. NMR 1995, 6, 135-140.

36. Anumula, K. R.; Taylor, P. B. Anal. Biochem. 1992, 203, 101-108. 


\section{Figure Legends}

Figure 1. Partial 1D proton and $2 \mathrm{D}{ }^{1} \mathrm{H}-{ }^{13} \mathrm{C}$ - HSQC spectrum of CPI-GC-N. Only the major residues belonging to the $[3)-\alpha-$ Galp- $(1 \rightarrow 4)-\beta-G l c N A c-(1 \rightarrow]$ repeats, as well as the PEtN and PCho substituents are labeled. The numbers indicate the protons/carbons within a given residue, not the different residues.

Figure 2. Partial 2D ${ }^{1} \mathrm{H}-{ }^{1} \mathrm{H}-\mathrm{COSY}$ (top), ${ }^{1} \mathrm{H}^{-13} \mathrm{C}-\mathrm{HSQC}$ (bottom, black), and ${ }^{1} \mathrm{H}-{ }^{13} \mathrm{C}-$ HMBC (bottom, grey) NMR spectra of CPI-GC-F at high contour level to show only the most intense peaks and demonstrating the predominance of the $[3)-\alpha-G a l p-(1 \rightarrow 4)-\beta-$ GlcNAc- $(1 \rightarrow]$ repeats.

Figure 3. Anomeric region of the 2D- ${ }^{1} \mathrm{H}-{ }^{1} \mathrm{H}-\mathrm{TOCSY}$ spectrum of CPI-GC-F. Refer to Table 3 for an explanation of the labels used.

Figure 4. Overlaid partial 2D ${ }^{1} \mathrm{H}-{ }^{1} \mathrm{H}-\mathrm{TOCSY}$ (black) and NOESY (grey) NMR spectra of CPI-GC-F. Colored lines indicate structural motifs: 1-dark blue, 2-orange, 3-pink, 4-red, 5-dark green, 6-violet, 7-light green, 8-light blue, 9-black.

Figure 5. Panel A: Structural motifs of CPI-GC-F identified by NMR; Panel B: Structural model of CPI-GC consistent with the NMR data. Triangles: Rha; squares: GIcNAc; diamond: GlcA; stars: Xyl; yellow circles: Gal; blue circles: Glc; hexagon: myo-inositol; PCer: phosphoceramide; black lines: $\beta$-glycosidic bonds; gray lines: $\alpha$-glycosidic bonds. The numbers indicate linkage positions. PCho and PEtN are omitted for lack of attachment information. 
Figure 6. Anomeric region of the ${ }^{1} \mathrm{H}-{ }^{1} \mathrm{H}-\mathrm{NOESY}$ (top), ${ }^{1} \mathrm{H}-{ }^{13} \mathrm{C}-\mathrm{HMBC}$ (bottom, black), and ${ }^{1} \mathrm{H}-{ }^{13} \mathrm{C}-\mathrm{HSQC}-\mathrm{TOCSY}$ (bottom, grey) NMR spectra of CPI-GC-F, showing the correlations between $\alpha-G I c A$ anomeric (D1) and inositol (T) signals. Inter-residue NOE contacts were found from D1 to T3, T4, and T5; Inter-residue HMBC cross peaks were detected between D-H1 and T-C4 and between D-C1 and T-H4.

Figure 7 . Two rotamers of the $\rightarrow 4)$ - $\alpha-G l c p A-(1 \rightarrow 4)$-myo-Ins disaccharide linkage showing the expected NOE contacts between D1 and T3 and T5 (top) and between D1 and T4 (bottom). 
Table 1. Results of methylation analysis of CPI-GC-N and CPI-GC-F in per cent GC-MS peak area.

\begin{tabular}{lcc}
\hline Residue & CPI-GC-N & CPI-GC-F \\
\hline Terminal Rhap & 4.9 & 2.0 \\
Terminal Xylp & 5.7 & 1.4 \\
2-linked Rhap & 8.1 & 9.6 \\
3-linked Rhap & 5.9 & 7.1 \\
Terminal Glcp & 4.6 & 1.2 \\
Terminal Galp & 16.3 & 2.3 \\
3,4-linked Rhap & $\mathrm{NF}$ & 0.8 \\
2,3-linked Rhap & 4.0 & 9.1 \\
3-linked Glcp & 2.3 & 7.1 \\
2,4-linked Rhap & $\mathrm{NF}$ & 6.7 \\
2,3,4-linked Rhap & $\mathrm{NF}$ & 2.5 \\
3-linked Galp & 11.5 & 12.6 \\
4-linked Glcp & 3.8 & 0.2 \\
3,4-linked Galp & 3.2 & 2.8 \\
Terminal GlcpNAc & 5.6 & 7.2 \\
4-linked GlcpNAc & 7.3 & 2.1 \\
3-linked GlcpNAc & 12.6 & 17.3 \\
6-linked GlcpNAc & 1.7 & 5.5 \\
3,4-linked GlcpNAc & 2.5 & 2.3 \\
\hline
\end{tabular}
NF: not found 
Table 2. Partial NMR chemical shift assignment of CPI-GC-N.

\begin{tabular}{|c|c|c|c|c|c|c|c|c|c|}
\hline \multirow[t]{2}{*}{ No. } & \multirow[t]{2}{*}{ Residue } & \multicolumn{7}{|c|}{ Chemical shift } & \multirow[t]{2}{*}{ NOE } \\
\hline & & 1 & 2 & 3 & 4 & 5 & 6 & $6^{\prime}$ & \\
\hline \multirow[t]{2}{*}{$\mathrm{A} 1$} & 3-a-Gal & 5.51 & 3.84 & 3.81 & 4.2 & 3.99 & 3.75 & 3.75 & C-3 \\
\hline & & 101.5 & 70.0 & 82.3 & 71.5 & 72.0 & 63.8 & & \\
\hline \multirow[t]{2}{*}{$\mathrm{A} 2$} & 3-a-Gal & 5.45 & 3.85 & 3.81 & 4.21 & ND & ND & ND & B-4 \\
\hline & & 101.8 & 70.1 & 82.3 & 71.5 & ND & ND & & \\
\hline \multirow[t]{2}{*}{ B } & $4-\beta-G l c N A c$ & 4.7 & 3.79 & 3.74 & 3.74 & 3.46 & 3.87 & 3.75 & A-3,4 \\
\hline & & 105.2 & 58.1 & ND & 81.1 & 78.1 & 63.1 & & \\
\hline \multirow[t]{2}{*}{ C } & 3- $\beta-G l c N A c$ & 4.73 & 3.87 & 3.79 & ND & 3.60 & ND & ND & \\
\hline & & 105.2 & 57 & 82.5 & ND & 77.1 & ND & & \\
\hline \multirow[t]{2}{*}{$D$} & $\alpha-G \mid c A$ & 5.32 & 3.69 & 3.99 & 3.83 & 4.77 & & & \\
\hline & & 101.5 & 73.8 & 76.2 & 72.9 & 73.1 & ND & & \\
\hline \multirow[t]{2}{*}{ E1 } & 2-a-Rha & 5.28 & 4.10 & 4.01 & ND & ND & ND & ND & \\
\hline & & 103.4 & 81.6 & 73.8 & ND & ND & ND & & \\
\hline \multirow[t]{2}{*}{ E2 } & 2-a-Rha & 5.02 & 4.18 & 3.73 & ND & ND & ND & ND & \\
\hline & & 104.3 & 80.9 & ND & ND & ND & ND & & \\
\hline \multirow[t]{2}{*}{$\mathrm{F} 1$} & 3-a-Rha & 5.24 & 4.12 & 4.19 & 3.81 & ND & ND & ND & \\
\hline & & 103.8 & 72.7 & 80.7 & ND & ND & ND & & \\
\hline \multirow[t]{2}{*}{$\mathrm{F} 2$} & 3-a-Rha & 5.10 & 4.04 & 3.89 & ND & ND & ND & ND & \\
\hline & & 104.8 & 72.7 & 78.8 & ND & ND & ND & & \\
\hline \multirow[t]{2}{*}{ F3 } & 3-a-Rha & 4.99 & 4.21 & 4.15 & ND & ND & ND & ND & \\
\hline & & 104.1 & 72.4 & 78.3 & ND & ND & ND & & \\
\hline \multirow[t]{2}{*}{$\mathrm{F} 4$} & 3-a-Rha & 4.96 & 4.29 & 4.02 & ND & ND & ND & ND & \\
\hline & & 104.3 & 71.5 & 80.2 & ND & ND & ND & & \\
\hline \multirow[t]{2}{*}{ G } & 2,3-a-Rha & 5.15 & 4.15 & 4.02 & 3.79 & ND & ND & ND & \\
\hline & & 103.4 & 79.5 & 80.2 & ND & ND & ND & & \\
\hline \multirow[t]{2}{*}{$\mathrm{H}$} & $\beta-X y l$ & 4.47 & 3.31 & 3.49 & 3.68 & 3.92 & 3.28 & & \\
\hline & & 104.8 & 75.9 & 78.3 & 72.0 & 68 & & & \\
\hline \multirow[t]{2}{*}{ I } & $\beta-$ Gal & 4.48 & 3.54 & 3.67 & 3.93 & ND & ND & ND & \\
\hline & & 105.5 & 73.6 & 75.2 & 70.3 & ND & ND & & \\
\hline \multirow[t]{2}{*}{ J } & PCho & 4.33 & 3.68 & 3.22 & & & & & \\
\hline & & 62.2 & 68.8 & 56.7 & & & & & \\
\hline \multirow[t]{2}{*}{$\mathrm{K}$} & PEtN & 4.12 & 3.28 & & & & & & \\
\hline & & 64.7 & 42.8 & & & & & & \\
\hline
\end{tabular}

ND: not determined 
Table 3. Partial NMR chemical shift assignments of CPI-GC-F.

\begin{tabular}{|c|c|c|c|c|c|c|c|c|c|}
\hline \multirow[t]{2}{*}{ No. } & \multirow[t]{2}{*}{ Residue } & \multicolumn{7}{|c|}{ Chemical shift (ppm) } & \multirow{2}{*}{$\begin{array}{l}\text { NOE/ } \\
\text { HMBC }\end{array}$} \\
\hline & & 1 & 2 & 3 & 4 & 5 & 6 & Intens & \\
\hline \multirow[t]{2}{*}{$A_{1}$} & 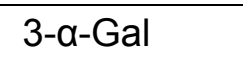 & 5.44 & 3.86 & 3.82 & 4.19 & 3.88 & $3.91 / 3.75$ & 10.7 & $\mathrm{~B}_{1}-4$ \\
\hline & & 101.2 & 69.8 & 81.8 & 71.2 & 73.0 & 62.8 & & \\
\hline \multirow[t]{2}{*}{$\mathrm{A}_{2}$} & 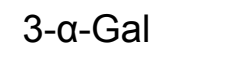 & 5.35 & 3.88 & 3.97 & 4.22 & ND & ND & 2.0 & R-3 \\
\hline & & 101.7 & ND & 81.6 & 71.2 & ND & ND & & \\
\hline \multirow[t]{2}{*}{$\mathrm{B}_{1}$} & $4-\beta-G \mid c N A c$ & 4.71 & 3.86 & 3.75 & 3.73 & 3.46 & $3.87 / 3.76$ & 10.3 & $A_{1}-3$ \\
\hline & & 105.0 & 56.7 & 72.9 & 81.3 & 78.0 & 62.8 & & \\
\hline \multirow[t]{2}{*}{$\mathrm{B}_{2}$} & $4-\beta-G \mid c N A c$ & 4.76 & 3.87 & 3.77 & 3.73 & 3.45 & ND & 1.1 & $A_{2}-3$ \\
\hline & & 105.0 & 56.7 & 72.9 & 81.3 & 78.0 & ND & & \\
\hline \multirow[t]{2}{*}{$\mathrm{C}_{1}$} & $3-\beta-G \mid c N A c$ & 4.85 & 3.85 & 3.61 & 3.60 & 3.55 & ND & 1.7 & \\
\hline & & 103.6 & 56.7 & 84.1 & 72.2 & 76.3 & ND & & \\
\hline \multirow[t]{2}{*}{$\mathrm{C}_{2}$} & $3-\beta-G I c N A c$ & 4.80 & 3.83 & 3.59 & 3.49 & ND & ND & 7.3 & \\
\hline & & 103.4 & 58.1 & 84.2 & ND & ND & ND & & \\
\hline \multirow[t]{2}{*}{ D } & 4-a-GlcA & 5.27 & 3.64 & 3.98 & 3.76 & 4.36 & & 5.3 & T-4 \\
\hline & & 101.7 & 74.1 & 76.2 & 78.7 & 75.0 & 178.6 & & \\
\hline \multirow[t]{2}{*}{$\mathrm{E}_{1}$} & $2-\alpha-R h a$ & 5.31 & 4.09 & 4.05 & ND & ND & ND & 1.3 & M-4 \\
\hline & & 103.6 & 81.6 & 72.7 & ND & ND & ND & & \\
\hline \multirow[t]{2}{*}{$E_{2}$} & $2-\alpha-R h a$ & 5.25 & 4.10 & 3.91 & ND & ND & ND & 2.9 & $F_{1-3}$ \\
\hline & & 103.6 & 81.6 & 71.8 & ND & ND & ND & & \\
\hline \multirow[t]{2}{*}{$E_{3}$} & $2-\alpha-R h a$ & 5.24 & 4.11 & 3.91 & 3.47 & 3.77 & 1.28 & 1.8 & $F_{1}-3$ \\
\hline & & 103.6 & 81.6 & 72.2 & 74.7 & 72.0 & 19.2 & & \\
\hline \multirow[t]{2}{*}{$\mathrm{E}_{4}$} & $2-\alpha-R h a$ & 5.15 & 4.26 & ND & ND & ND & ND & 4.0 & $\mathrm{~F}_{5}-3$ \\
\hline & & 102.7 & 80.6 & ND & ND & ND & ND & & \\
\hline \multirow[t]{2}{*}{$\mathrm{F}_{1}$} & 3-a-Rha & 5.19 & 4.05 & 3.79 & ND & ND & ND & 0.3 & \\
\hline & & ND & 72.7 & 81.6 & ND & ND & ND & & \\
\hline \multirow[t]{2}{*}{$\mathrm{F}_{2}$} & 3-a-Rha & 5.16 & 4.01 & 3.75 & 3.51 & 3.7 & 1.32 & 1.2 & \\
\hline & & 103.2 & 71.5 & 81.6 & 74.4 & 72 & 19.6 & & \\
\hline \multirow[t]{2}{*}{$\mathrm{F}_{3}$} & 3-a-Rha & 5.14 & 4.39 & 3.89 & 3.53 & ND & ND & 1.3 & $\mathrm{G}_{1}-3$ \\
\hline & & 102.9 & 73.1 & 82.0 & 74.2 & ND & ND & & \\
\hline \multirow[t]{2}{*}{$\mathrm{F}_{4}$} & 3-a-Rha & 5.07 & 4.03 & 3.75 & 3.50 & 3.79 & 1.28 & 3.2 & $\mathrm{G}_{2}-3$ \\
\hline & & 104.5 & 72.4 & 81.4 & 74.3 & 71.7 & 19.2 & & \\
\hline \multirow[t]{2}{*}{$\mathrm{F}_{5}$} & 3-a-Rha & 4.99 & 4.21 & 3.79 & ND & ND & ND & 2.2 & \\
\hline & & 103.8 & 71.3 & 80.0 & ND & ND & ND & & \\
\hline \multirow[t]{2}{*}{$\mathrm{F}_{6}$} & 3-a-Rha & 4.84 & 4.25 & 3.80 & 3.48 & ND & 1.25 & 0.7 & \\
\hline & & 103.8 & 72.2 & 79.9 & 74.6 & ND & 19.2 & & \\
\hline \multirow[t]{2}{*}{$\mathrm{G}_{1}$} & 2,3-a-Rha & 5.29 & 4.07 & 4.01 & 3.55 & 3.68 & 1.23 & 1.1 & \\
\hline & & 103.6 & 81.6 & 79.9 & 76 & 71.9 & 19.2 & & \\
\hline $\mathrm{G}_{2}$ & 2,3-a-Rha & 5.02 & 4.19 & 3.86 & 3.61 & 3.79 & 1.28 & 3.8 & \\
\hline
\end{tabular}




\begin{tabular}{|c|c|c|c|c|c|c|c|c|c|}
\hline \multirow[t]{2}{*}{ No. } & \multirow[t]{2}{*}{ Residue } & \multicolumn{7}{|c|}{ Chemical shift (ppm) } & \multirow{2}{*}{$\begin{array}{l}\text { NOE/ } \\
\text { HMBC }\end{array}$} \\
\hline & & 1 & 2 & 3 & 4 & 5 & 6 & Intens & \\
\hline & & 104.5 & 80.6 & 78.7 & 75.5 & 71.7 & 19.2 & & \\
\hline \multirow[t]{2}{*}{$\mathrm{G}_{3}$} & 2,3-a-Rha & 4.95 & 4.29 & 3.89 & ND & ND & 1.25 & 1.5 & $\mathrm{~N}-4$ \\
\hline & & 104.3 & 80.6 & 82.2 & ND & ND & 19.2 & & \\
\hline \multirow[t]{2}{*}{$\mathrm{G}_{4}$} & 2,3-a-Rha & 5.05 & 4.36 & 3.86 & ND & ND & ND & 5.6 & \\
\hline & & 102.0 & 81.0 & 81.6 & ND & ND & ND & & \\
\hline \multirow[t]{2}{*}{$\mathrm{H}_{1}$} & $\beta-X y l$ & 4.67 & 3.29 & 3.43 & 3.60 & 3.93 & 3.30 & 0.2 & $E_{4}-2$ \\
\hline & & 105.2 & 75.7 & 78.9 & 71.7 & 67.5 & & & \\
\hline \multirow[t]{2}{*}{$\mathrm{H}_{2}$} & $\beta-X y l$ & 4.61 & 3.30 & 3.42 & 3.61 & 3.93 & 3.29 & 2.5 & $\mathrm{G}_{4}-2$ \\
\hline & & 105.2 & 75.7 & 78.9 & 71.7 & 67.5 & & & \\
\hline \multirow[t]{2}{*}{$\mathrm{H}_{3}$} & $\beta-X y l$ & 4.54 & 3.32 & 3.43 & 3.59 & 3.99 & 3.30 & 1.4 & \\
\hline & & 105.2 & 75.7 & 78.9 & 71.7 & 67.9 & & & \\
\hline \multirow[t]{2}{*}{$\mathrm{H}_{4}$} & $\beta-X y l$ & 4.48 & 3.23 & 3.43 & ND & 3.97 & ND & 1.6 & \\
\hline & & 105.3 & 76.1 & 78.9 & ND & ND & & & \\
\hline \multirow[t]{2}{*}{$\mathrm{H}_{5}$} & $\beta-X y l$ & 4.45 & 3.23 & 3.44 & 3.63 & 3.97 & 3.30 & 1.2 & \\
\hline & & 105.3 & 76.1 & 78.9 & 71.7 & ND & & & \\
\hline \multirow[t]{2}{*}{ I } & $\beta$-Gal & 4.47 & 3.54 & 3.66 & 3.91 & 3.72 & ND & 2.0 & $\mathrm{~B}_{2}-4$ \\
\hline & & 105.5 & 74.1 & 75.2 & 71.9 & 77.8 & ND & & \\
\hline \multirow[t]{2}{*}{ L } & $\alpha-G a l$ & 5.43 & 3.79 & 3.77 & 3.97 & ND & ND & 1.7 & \\
\hline & & 101.5 & 71.2 & 71.7 & 71.2 & ND & ND & & \\
\hline \multirow[t]{2}{*}{ M } & 4-a-Gal & 5.39 & 3.87 & 4.03 & 4.30 & 4.39 & ND & 0.2 & \\
\hline & & 101.7 & 71.9 & 72.5 & 79.2 & 73.4 & ND & & \\
\hline \multirow[t]{2}{*}{$\mathrm{N}$} & 3,4-a-Gal & 5.37 & 3.83 & 3.90 & 4.00 & ND & ND & 1.4 & \\
\hline & & 101.7 & 71.7 & 82.3 & 79.9 & ND & ND & & \\
\hline \multirow[t]{2}{*}{$\mathrm{O}$} & $\beta-G \mid c N A c$ & 4.66 & 3.74 & 3.56 & 3.46 & 3.46 & ND & 0.5 & \\
\hline & & 105.2 & 58.1 & 76.0 & 72.2 & 78.0 & ND & & \\
\hline \multirow[t]{2}{*}{$P$} & $6-\beta-G l c N A c$ & 4.56 & 3.70 & 3.60 & 3.53 & 3.56 & $4.18 / 3.91$ & 2.5 & $\mathrm{G}_{2}-2$ \\
\hline & & 105.5 & 58.4 & 76.9 & 73.4 & 76.8 & 70.5 & & \\
\hline \multirow[t]{2}{*}{$Q$} & 3-a-Glc & 5.46 & 3.58 & 3.84 & 3.44 & 3.71 & $3.77 / 3.72$ & 3.3 & D-4 \\
\hline & & 100.5 & 74.1 & 84.1 & 70.1 & 74.1 & 63.0 & & \\
\hline \multirow[t]{2}{*}{$\mathrm{R}$} & 3- $\beta-G \mid c$ & 4.5 & 3.45 & 3.66 & 3.49 & 3.49 & ND & 2.2 & P-6 \\
\hline & & 105.5 & 76.2 & 84.4 & 71.0 & 78.0 & ND & & \\
\hline \multirow[t]{2}{*}{$S$} & $\beta-G \mid c$ & 4.45 & 3.31 & 3.48 & 3.39 & 3.45 & ND & 1.7 & \\
\hline & & 105.5 & 75.5 & 78.4 & 72.2 & 78.0 & ND & & \\
\hline \multirow[t]{2}{*}{$\mathrm{T}$} & 4-Ins & 3.52 & 4.02 & 3.73 & 3.71 & 3.37 & 3.64 & 8.0 & \\
\hline & & 73.4 & 74.8 & 72.9 & 83.0 & 75.2 & 75.1 & & \\
\hline
\end{tabular}

ND: not determined 
Table 4. Compositional analysis (in mol\%) of CPI-GC-F by NMR and GC-MS

\begin{tabular}{lrc}
\hline Residue & NMR & GC-MS \\
\hline Gal & 18.0 & 19.3 \\
GlcNAc & 23.3 & 25.3 \\
GlcA & 5.3 & 1.0 \\
Rha & 31.1 & 35.0 \\
Xyl & 6.9 & 4.4 \\
Glc & 7.3 & 11.4 \\
Ins & 8.0 & 3.6 \\
\hline
\end{tabular}


Figure 1

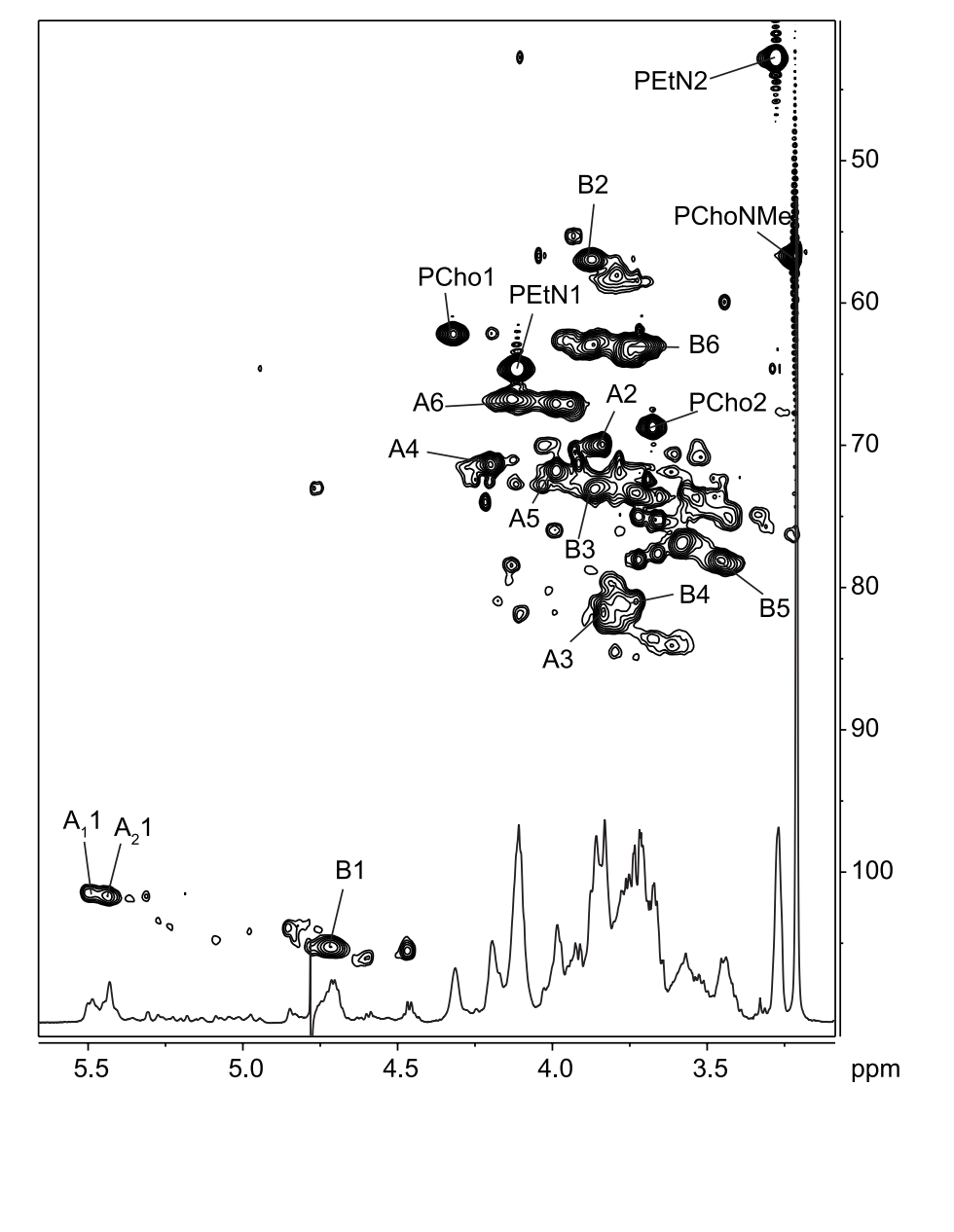

(1)

m

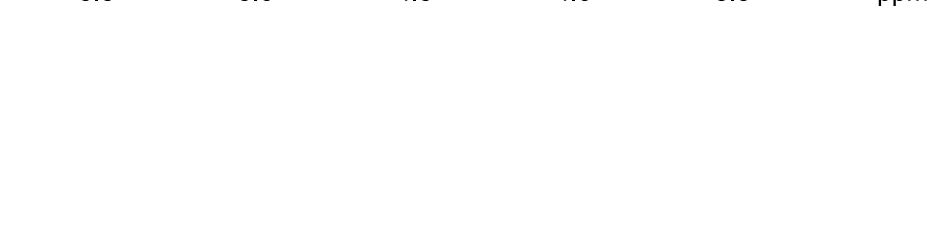


Figure 2

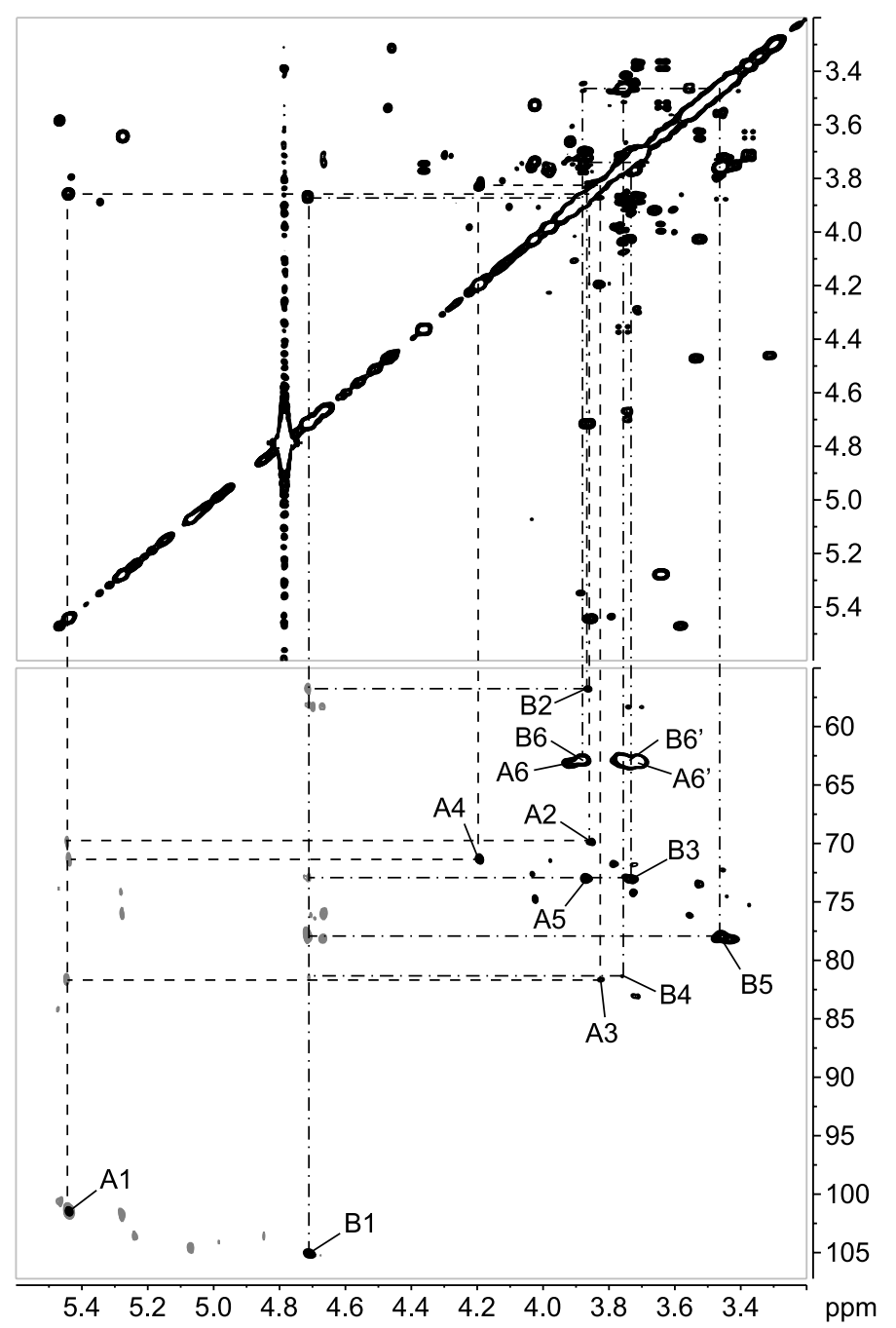


Figure 3

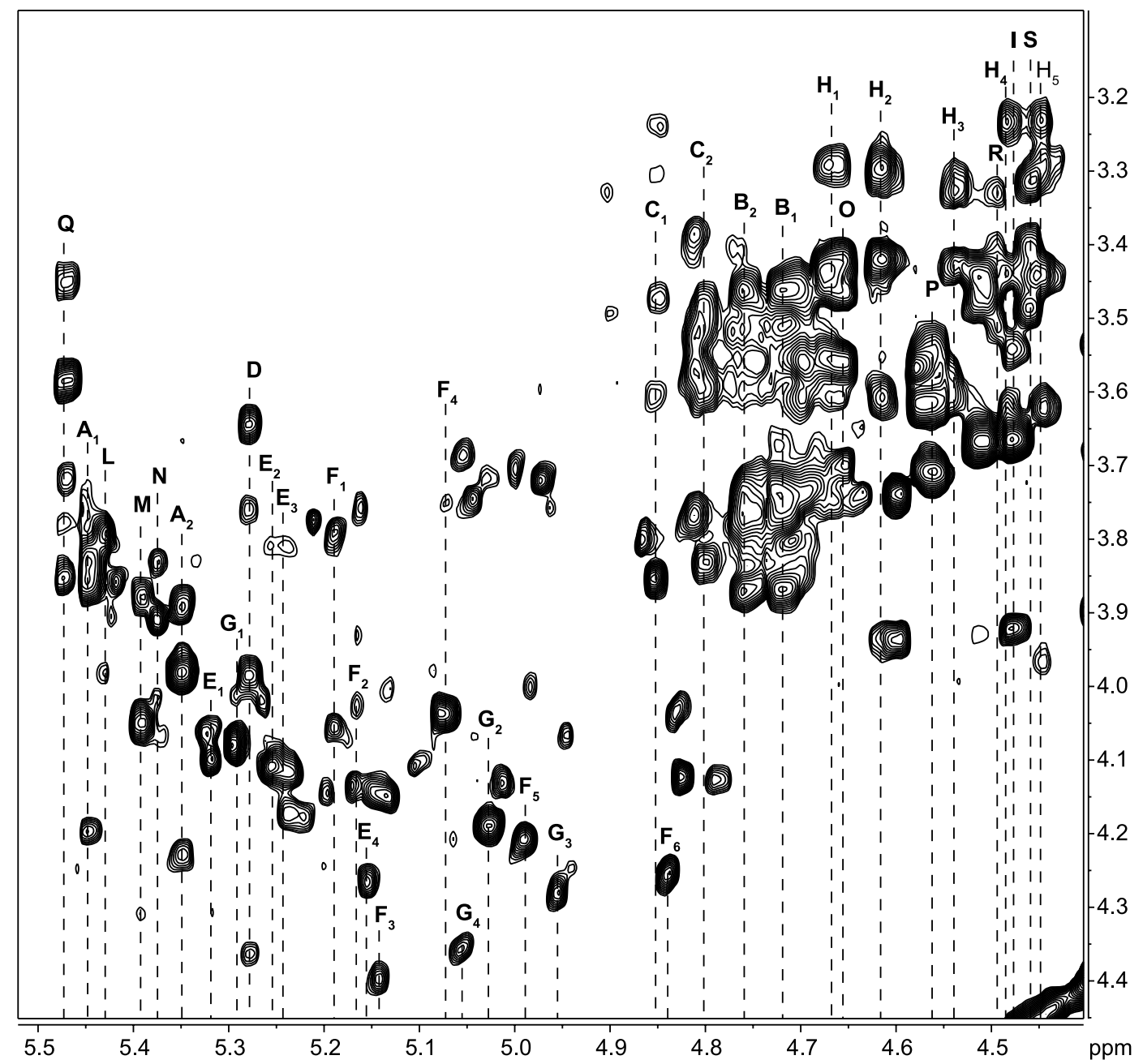




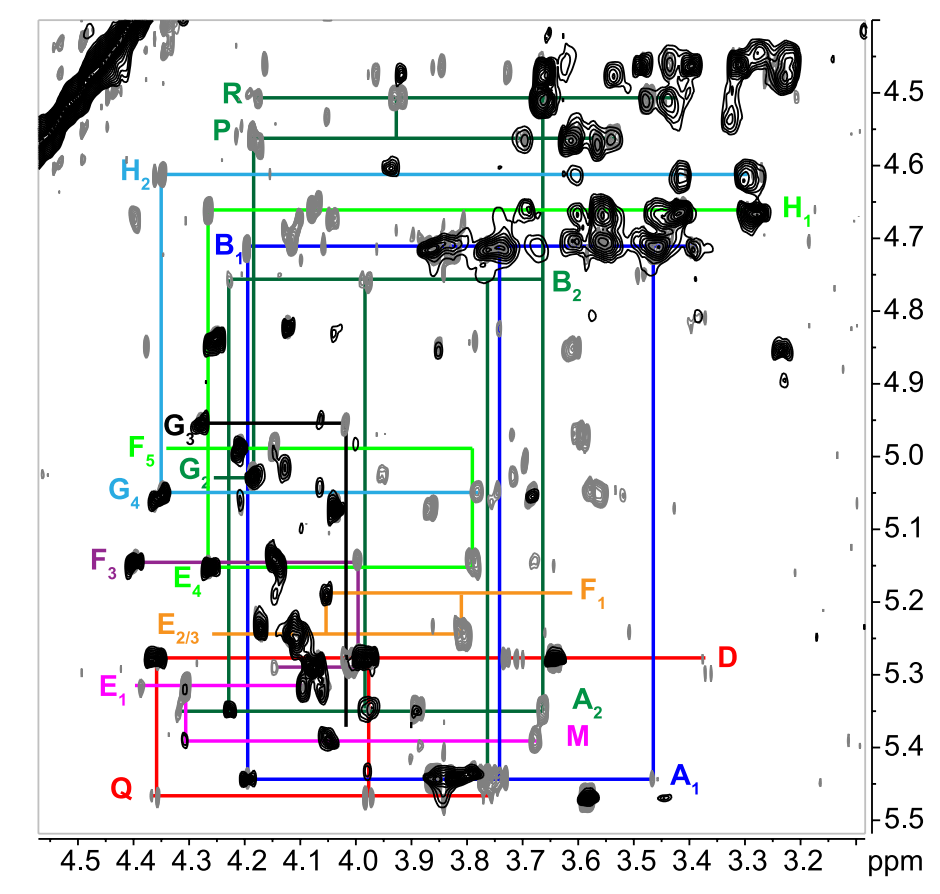

Figure 4 (1) 5.4
5.5
0.5
pom
5

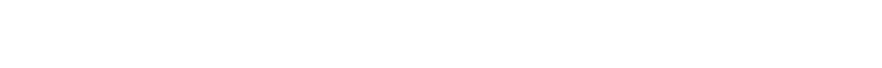

.

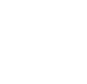


Figure 5

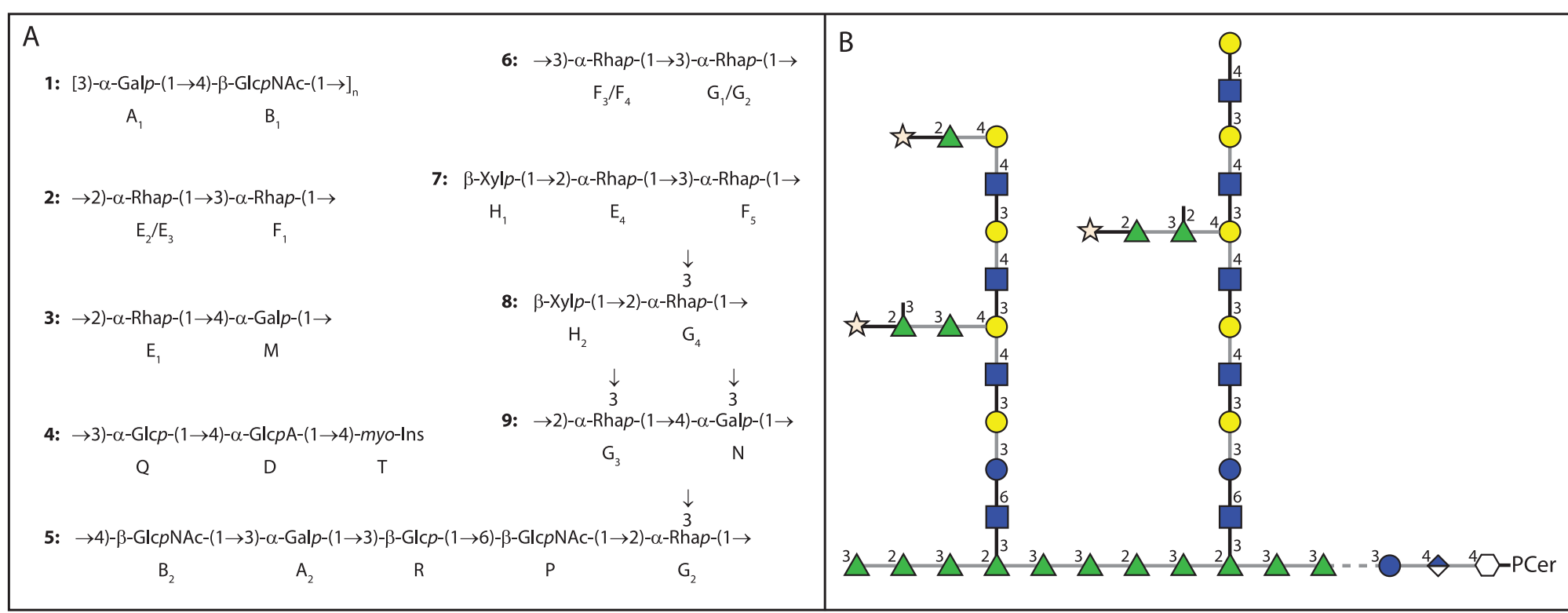




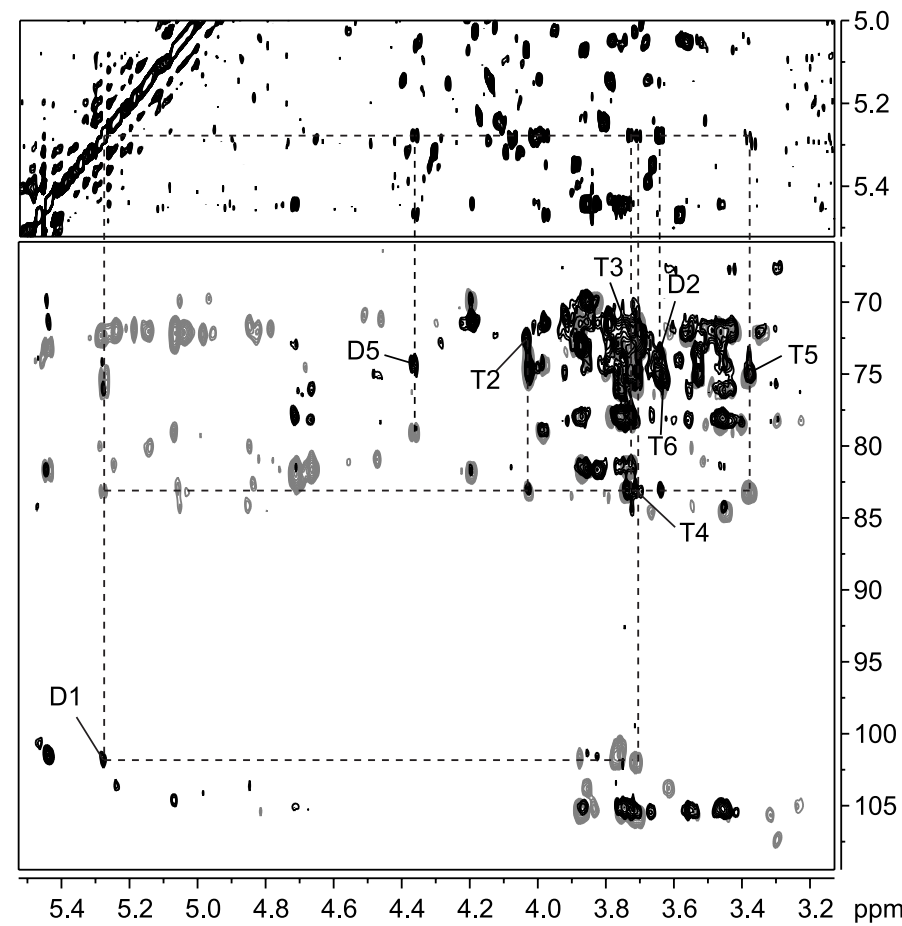



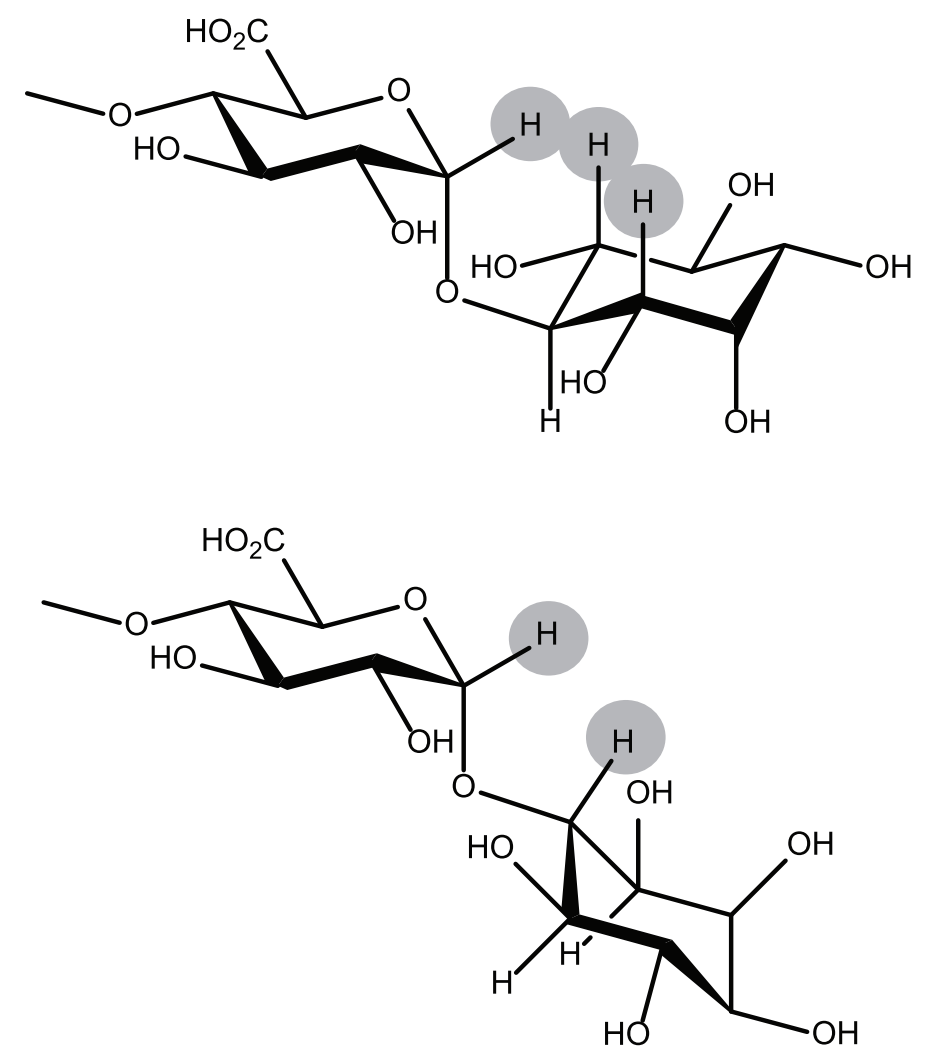


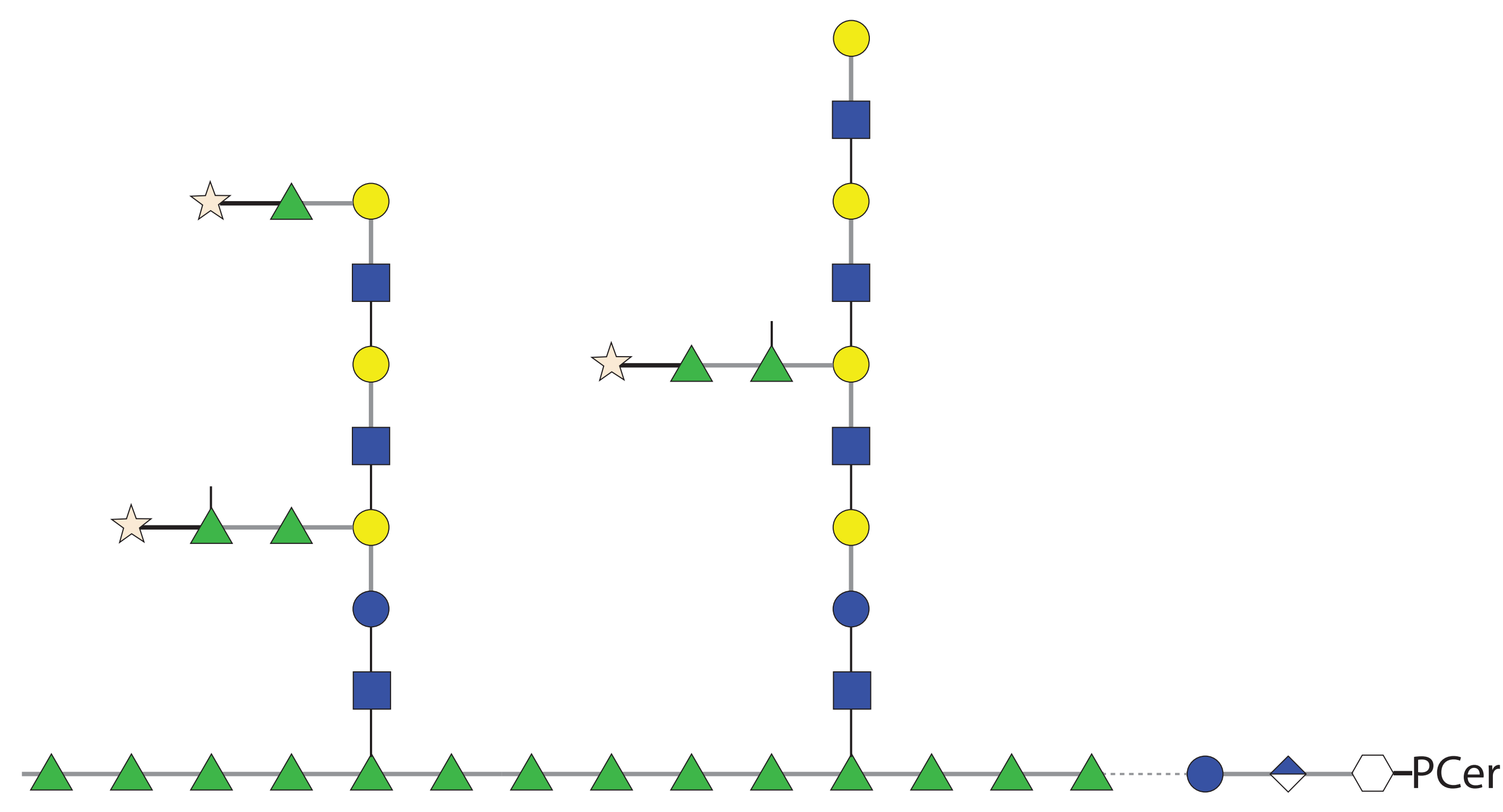
Galactose
- GlcNAc
$\triangle$ Rhamnose
is Xylose
- Glucose
$\diamond \quad$ Glucuronic acid
$\square$ myo-Inositol
PCer Phosphoceramide
- $\alpha$-glycosidic bond
- $\beta$-glycosidic bond 